\title{
Values of Head circumference and Body Height in Sohag children from birth to six years.
}

\section{By}

Sayed Anwar Sayed,(1), Salwa M. Ouies(2),WalaaN. Elsamman,(3)

1. Prof. of Anatomy \& Embryology, Faculty of Medicine, Assiutuniversity.

2. Lecturer of Human anatomy \& Embryology, Faculty of Medicine, Sohag University..

3. Assistant Lecturer of Human anatomy \& Embryology, Faculty of Medicine, Sohag

University.

\begin{abstract}
Introduction:Growth reference values should be based on a representative sample of the population; for determining growth velocity, longitudinal data are required.The growth supervision of children usinggrowth curves is a widespread and usefultool in general pediatric practice.Head circumference $(\mathrm{HC})$ is one of the anthropometric parameters included in the physical examination of the infant and toddler.Due to the differences in the international and interracial standard charts of anthropometric indices, several researchers around the world have attempted to provide alternative standard charts for measuring the $\mathrm{HC}$ at different ages.
\end{abstract}

Aim of the work: The present study was carried out to obtain head circumference and body height values for children from birth to six years.Subjects and methods: The study included 1300 child (boys and girls) in different ages from birth to six years and 20 years of sohag governorate in Upper Egypt.The children divided into different ages (at birth, 2 months, 4 months, 6 months, 9 months, 12 months, 18 months, 24 months, 3 years, 4 years, 5years and 6years) and in each age there is $\mathbf{5 0}$ boy and $\mathbf{5 0}$ girl. Head circumference and Body Height were measured andcompared between boys and girls.

Results: The mean values of head circumference and body height increase with increase in age and the values were higher in boys than girls in all ages.

Conclusion: the growth velocity is higher in boys than in girls in all ages.

Keywords :Head circumference,height,Sohag, children

\section{INTRODUCTION}

Assessment of growth for age based on anthropometric measurements is an important and reliable method in the monitoring of health in an individual child(1).

Head circumference is one of the most significant findings in physical examination of children, especially in the evaluation of the development and early diagnosis of neurological disorders $(\mathbf{2 , 3})$.

Standard head circumference (HC) charts are of foremost significance because, unlike other somatic growth parameters, even small deviations of the HC from the normal range could be associated with various diseases $(\mathbf{4 , 5})$.

The formation of the skull is a complex interaction reflecting the growth of both the bones and the brain as the major stimulus for skull growth. Head growth is a dynamic process and plotting serial measurements of $\mathrm{HC}$ over a period of time could provide useful information in this regard (6).

The head growth is more rapid in the first years of life; therefore, most head circumference growth charts have been produced for this time period. Head circumference reaches approximately $\mathbf{9 0 \%}$ of the adult size at $\mathbf{3}$ years and $\mathbf{9 5 \%}$ at $\mathbf{5}$ years of age(7).

In early infancy the skull bones are not fused, which allows for brain growth. The rate of increase in $\mathrm{HC}$ differs for different ages. During the first three months it is 3 $\mathrm{cm}$ per month, and then the anterior fontanel closes between 9-18 months. For children between $\mathbf{4}$ and $\mathbf{6}$ years of age, HC growth is only one $\mathrm{cm}$ per year $(\mathbf{8})$. 
Head circumference of more than 2 standard deviation above or below the mean of the head circumference at a given age and sex is considered abnormal (macrocephaly or microcephaly, respectively)(9).

Any significant reductions in head circumference found in malnourished children may have serious implications for their future performance and achievement(10).

Aim of the work : to obtain reference values for head circumference \& body height for children from birth to six years then study the differences between values in boys with girls.

\section{Subjects and methods}

Children studied:The study included 1300 child (boys and girls) in different ages from birth to six years and 20 years of Sohag governorate in Upper Egypt. The study was done during 2016.

The data collected from hospitals, kinder gartens, walfare health centers and primary schools.

Children studied according to age were 50boys and 50 girls at birth, 2 months, 4 months, 6 months, 9 months, 12 months, 18 months, 24 months, 3 years, 4years, 5years and 6years. The children were examined clinically to exclude any deformity or an apparent disease. Apparently normal children were included in the present study.

\section{Methods for measurements}

1-The head circumference:The tape placed horizontally above ears and midway between the eye brows and the hair line to the occipital prominence on the back of the head (11), this measure was repeated three times and the largest measure was taken.

\section{2-The body stature(length/height):}

Children below two years: the height was measured by lying down on a scale, the length of the toddler was measured without any clothing, including the nappy, which can distort the hips and shorten the length measurement. The length measurement is then read off the scale, to the nearest $1 / 2 \mathrm{~cm}(\mathbf{1 2})$.

Children after two years: The toddler was wearing light underwear, without socks and shoes. He or she stands upright with heels, buttocks and shoulders touching the stadiometer and look straight ahead with the corner of the eyes horizontal with the middle of the ear. (12).

The data were statistically analysed using SPSS soft ware version 16. Results were expressed as mean value $(\mathrm{X}-) \pm$ standard deviation (SD). Student t test was used to compare results in girls and boys.A probability value of $\mathbf{P}<\mathbf{0 . 0 5}$ was considered significant and $\mathbf{P}<\mathbf{0 . 0 1}$ was highly significant. 
SOHAG MEDICAL JOURNAL

Vol. 21 No.1 Jan 2017

\section{Results}

The mean values (x-) of the head circumference (HC) and body height for the studied childrenfrom birth to $\mathbf{6}$ yearsare presented in table (1).

It is evident from table (1) that there is an increase in head circumference and height in children with the increase of age. MeanHC of girls was less than in boys in all the

studied age groups (Fig.1). Differences were significant at $\mathbf{1 8}$ months and highly significant at birth, $\mathbf{2}$ months, $\mathbf{6}$ months, 12 months and 5 years.

Mean heights of girls was less than height of boys in all the studied age groups (fig.2).Differences were significant at $\mathbf{2}$ months and highly significant at $\mathbf{4}$ months, 6 months, 9 months, 12 months and $\mathbf{2 4}$ months.

Table 1 showing the mean values of (X-) and (SD) of head circumference $(\mathrm{cm})$ and body height of sohag children aged from birth to 6 years.

\begin{tabular}{|c|c|c|c|c|c|c|}
\hline \multirow[t]{2}{*}{ Age } & \multicolumn{3}{|c|}{$\begin{array}{l}\text { Head circumference } \\
(\mathrm{X}- \pm \text { SD) }\end{array}$} & \multicolumn{3}{|l|}{$\begin{array}{l}\text { Body height } \\
\text { (X- } \pm \text { SD) }\end{array}$} \\
\hline & $\begin{array}{l}\text { Boys } \\
\text { n=50 }\end{array}$ & $\begin{array}{c}\text { Girls } \\
\mathbf{n}=\mathbf{5 0}\end{array}$ & $\mathbf{D}$ & $\begin{array}{l}\text { Boys } \\
\text { n=50 }\end{array}$ & $\begin{array}{c}\text { Girls } \\
\mathbf{n}=\mathbf{5 0}\end{array}$ & $\mathbf{D}$ \\
\hline At birth & $34.35 \pm 1.25$ & $32.83 \pm 1.75$ & $1.525 * *$ & $53.07 \pm 2.52$ & $52.85 \pm 1.75$ & .225 \\
\hline 2 months & $38.75 \pm 1.48$ & $37.78 \pm 1.63$ & $.96 * *$ & $60.20 \pm 1.92$ & $59.38 \pm 1.64$ & $.81 *$ \\
\hline 4 months & $40.023 \pm 1.60$ & $39.81 \pm 1.15$ & .213 & $63.88 \pm 1.08$ & $62.66 \pm 1.15$ & $1.22 * *$ \\
\hline 6 months & $44.16 \pm .756$ & $41.56 \pm .934$ & $2.6^{* *}$ & $68.49 \pm 1.64$ & $67.108 \pm 1.84$ & $1.41 * *$ \\
\hline 9 months & $44.40 \pm .748$ & $43.56 \pm .733$ & .91 & $71.84 \pm .803$ & $71.18 \pm 1.30$ & $.66 * *$ \\
\hline 12 months & $47.41 \pm .881$ & $45.79 \pm .699$ & $1.61 * *$ & $78.5 \pm 3.541$ & $74.27 \pm 1.05$ & $3.32 * *$ \\
\hline 18 months & $47.56 \pm 1.325$ & $46.71 \pm 1.23$ & $.82 *$ & $82.93 \pm 1.32$ & $81.42 \pm 1.25$ & 1.51 \\
\hline 24 months & $48.34 \pm .92$ & $48.10 \pm 1.647$ & .24 & $93.667 \pm 4.195$ & $87.73 \pm 3.136$ & $5.33 * *$ \\
\hline 3 years & $49.22 \pm 1.47$ & $49.1 \pm 1.838$ & .12 & $98.3 \pm 2.67$ & $97.56 \pm 3.072$ & .733 \\
\hline 4 years & $50.1 \pm 1.49$ & $49.7 \pm 1.60$ & .225 & $102.2 \pm 3.33$ & $101.8 \pm 2.846$ & .4 \\
\hline 5 years & $50.63 \pm .986$ & $49.82 \pm .977$ & $.8 * *$ & $109.33 \pm 3.316$ & $108.03 \pm 2.756$ & .3 \\
\hline 6 years & $51.35 \pm 2.02$ & $50.725 \pm 1.60$ & .63 & $109.45 \pm 2.838$ & $108.982 \pm 3.527$ & .47 \\
\hline
\end{tabular}

$\mathrm{X}$ - = mean value in $\mathrm{cm}, \mathrm{SD}=$ standard deviation ,

$\mathrm{D}=$ difference between means of boys and girls, $\mathbf{n}=$ number of cases in each age group, *Significant at $\mathbf{p}<0.05, * *$ highly significant at $\mathbf{p}<0.01$ 


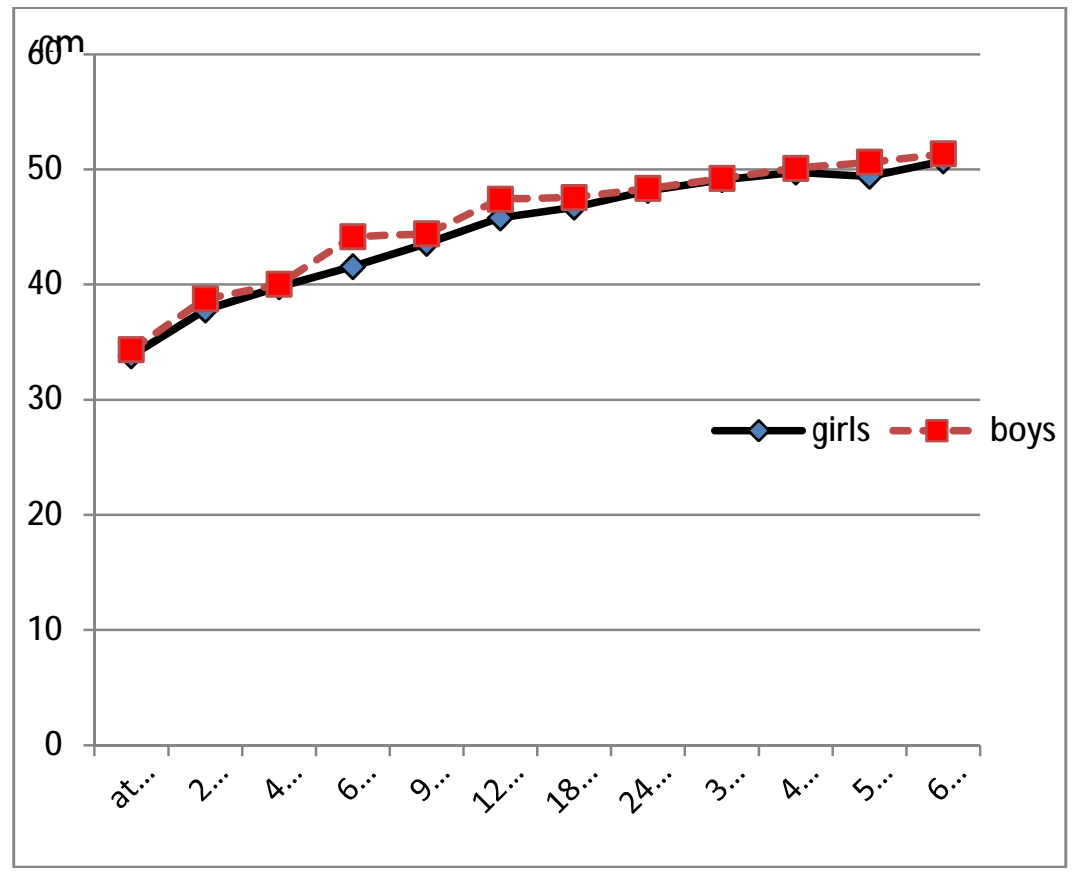

Figure (1) shows a comparison between the mean values of head circumference between boys and girls (0-6years).

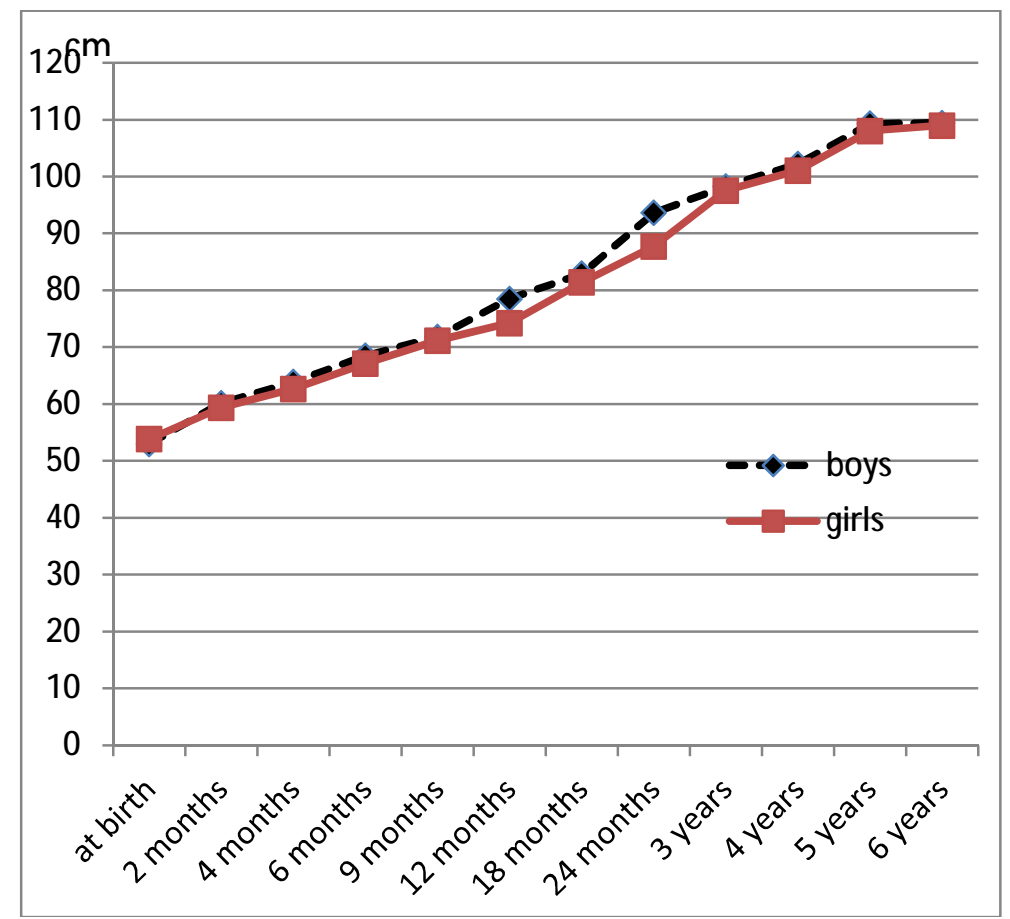

Figure (2) shows a comparison between the mean values of body stature between boys and girls (0-6years)

\section{Discussion}

The present study aimed to obtain reference values for head circumference (HC) and body height for boys and girls of Sohag governorate aged from birth to six years.It viewed also the differences between the mean values of head 
circumference and height in boys and girls for each age.

The present work studied the ages from birth to six years as most of development of head occurs in these years that supported by previous studiesthat found that the most significant increase in the $\mathrm{HC}$ size occurs within the first few years of life. It grows as much as $\mathbf{8 0 \%}$ of the adult size by two years with the pace slowing down afterwards (2).

The present study revealed that there was increase in head circumference with increase in age in boys and girls, the increase is maximum at first and second year that the $\mathrm{HC}$ increase by about $12 \mathrm{~cm}$ in boys and girls in the first year and by about $2 \mathrm{~cm}$ in boys and $\mathbf{3} \mathrm{cm}$ in girls in the second year ,furtherly the increase level become lower than the first two years thatbecome about one $\mathrm{cm}$ per year.

These results were in acceptance with an Egyptian study observed that there was a progressive increase in head circumference values in all age intervals for both sexes. The highest increase was during the first $\mathbf{2}$ years of life: $\mathbf{6} \mathrm{cm}$ during the first $\mathbf{6}$ months, 2 $\mathrm{cm}$ during the second half of the first year and $2 \mathrm{~cm}$ during the second year of life(13).

Similarly a Colombianstudy in $\mathbf{2 0 1 6}$ observed that head circumference at birth was $34.2 \mathrm{~cm}$ (SD 1.3)/33.8 $\mathrm{cm}$ (SD 1.2) for boys/girls, and during the first year of life mean head circumference increased by 12.9/11.9 $\mathrm{cm}$. In the second and third year, the increase was only 1.5 and $1.0 \mathrm{~cm}$ in boys and 2.0 and $0.9 \mathrm{~cm}$ in girls (14).

A study on head circumference in Iranian infants found that the HC size is likely to grow with age and it occurs rapidly within the first year of the infant's life. However, the rate of increase noticeably lowers in the second year of life(15).
For both sexes, in the first year of life head growth is more rapid than in the second year of life. The maximum range of $\mathrm{HC}$ in Ethiopian boys for the age group $0-1$ year is $11.40 \mathrm{~cm}$ and in girls $10.42 \mathrm{~cm}$; whereas it is $1.75 \mathrm{~cm}$ and $1.92 \mathrm{~cm}$ respectively for boys and girls in the age group from 1-2yr (16).

In the present study the mean values of $\mathrm{HC}$ are higher in boys than girls in all ages. The differences were significant $(\boldsymbol{P}<\mathbf{0 . 0 5})$ at18 months and highly significant $(P<\mathbf{0 . 0 1})$ at birth, 2 months, 6 months, 12 months and 5 years.

These results were in acceptance with previous study on Turkish Childrenreported that mean head circumference values of boys were larger than those of girls at all ages. Before puberty, the head circumference of boys is approximately $1 \mathrm{~cm}$ larger than that of girls; at the age of 12.5-12.99 years, the difference is only $0.54 \mathrm{~cm}$ due to the earlier onset of puberty in girls; however, after puberty, the difference gradually increases and reaches $\mathbf{1 . 6 7}$ $\mathrm{cm}$ between $\mathbf{1 7 . 5}$ and $\mathbf{1 7 . 9 9}$ years of age, also proved that there is significant correlations between height and head circumference(17).

Similarly a study of head circumference for school aged children from Western Romania revealed that boys show significantly larger head circumference compared to girls at any age(18). Furtherly Canadian study on infants at birth showed that weight and head circumference measurements in boys were higher than in girls(19).

The present study revealed that body height also showed increase in value with increase in age and the mean values of body height is higher in boys than girls in all ages. The differences were significant $(\boldsymbol{P}<\mathbf{0 . 0 5})$ at 2 months and highly significant $(P<\mathbf{0 . 0 1})$ at 4 months, $\mathbf{6}$ months, $\mathbf{9}$ months, $\mathbf{1 2}$ months and $\mathbf{2 4}$ months. 
An Egyptian study on children from one month to $\mathbf{1 8}$ years proved that the mean height of boys was slightly greater than girls during the first $\mathbf{1 0}$ years of life; the differences were significant only at ages 4,5 and 7 years (13).

Another Egyptian study on children in south Sinai proved that the mean of body height were higher for boys than girls during the first $\mathbf{8}$ years of age with significance only at age $\mathbf{3}$ years $(P<0.05)(20)$.

FurtherlyMalaysian study for children under six years old found that body length varied the most among infants and toddlers (aged 1-3 years old), especially at $\mathbf{1}$ year of age. (21)

Head growth is more rapid in the first years of life. Head circumference reaches approximately $\mathbf{9 0 \%}$ of the adult size at $\mathbf{3}$ years and $\mathbf{9 5 \%}$ at $\mathbf{5}$ years of age (6). The head circumferences reach about $\mathbf{8 0 \%}$ of adult size at 2 years (22).

\section{Conclusion}

Mean values of $\mathrm{HC}$ andbody height increase with increase in age and values in boys were higher than girls in all ages. The differences of HC were significant $(P<\mathbf{0 . 0 5})$ at 18 months and highly significant $(P<\mathbf{0 . 0 1})$ at birth, 2 months, 6 months, 12 months and 5 years. The differences of body height were significant $(\boldsymbol{P}<\mathbf{0 . 0 5})$ at 2 months and highly significant $(P<\mathbf{0 . 0 1})$ at 4 months, $\mathbf{6}$ months, $\mathbf{9}$ months, 12 months and $\mathbf{2 4}$ months.

\section{References}

1- Neyzi O, Bundak R, Gokcay G, Gunoz H, Furman A, Darendeliler $F$ and Baş $\mathbf{A}(\mathbf{2 0 1 5})$ : Reference Values for Weight, Height, Head Circumference, and Body Mass Index in Turkish Children, J Clin Res Pediatr Endocrinol.7(4):280-293 .

2- KarabiberH ,Durmaz Y, Yakinci C, Kutlu $\mathbf{O}$, Gumusalan $\mathbf{Y}$, Yologlu S and Yalaz K (2001):Head circumference measurement of urban children aged between 6 and 12 in Malatya, Turkey. Brain\& development, 23(8):801-4.

3- Sanna E, Palmas L, Tedesco $\mathrm{N}$ and Floris G(2003): The need of specific standards for head dimensions of urban Sardinian boys. AnthropologischerAnzeiger, 61(2):245-51.

4- Nilsson D, SvenssonJ,Korkmaz BA, Nelvig $H$ and Tisell $M$ (2013): Decreased head circumference in shunt-treated compared with healthy children

NeurosurgPediatr;12(5):483 90.

5- Morgan C, McGowan P, Herwitker S, Hart AE and Turner MA.(2014):Postnatal head growth in preterm infants: a randomized controlled parenteral nutrition study. Pediatrics. 133(1):e120-8.

6- Pedersen $M$, von Stedingk $H$, Botsivali M, Agramunt S, Alexander J, Brunborg G, Chatzi L, et al(2012): Birth weight, head circumference, and prenatal exposure to acrylamide from maternal diet: the European prospective mother-child study (NewGeneris). Environ Health Perspect. 120(12):1739-45.

7- Cameron N and Hawley NL(2010): Should the UK use WHO growth charts? Paediatr Child Health. 20(4):151-156.

8- MenounouA(2011): Head Size: is it important?:Paediatric Neurology 16 . ACNR . Volume 11 Number 2.

9- Geraedts EJ, Dommelen PV , Caliebe J , Visser R, Ranke M B , Buuren $S \mathrm{~V}$, Wit $J \mathbf{M}$ and Oostdijk W(2011):Association between Head Circumference and Body Size .Horm Res Paediatr;75:213-219.

10- Oyedeji GA, Olamijulo, Osinaike AL, Esimai VC, Odunusi EO and AladekomoTA(1997) : Head circumference of rural Nigerian children the effect of malnutrition on 
brain growth. Central African journal of medicine, 1997, 43(9):264-8.

11- ZahlSM , and Wester K(2008) : Routine measurement of head circumference as a tool for detecting intracranial expansion in infants: what is the gain ? A nationwide survey. Pediatrics. 121(3):e416-20.

12- WHO Multicentre Growth Reference Study Group (2006): WHO Child Growth Standards: length/height-for-age, weight-for-age, weight-for-length, weight-for height and body mass index-for-age: methods and development. Geneva: World Health Organization.

13- ZakiME, El-masry $S$ and Hassan NE(2008): Head circumference reference data for Egyptian children and adolescents. Eastern Mediterranean Health Journal.14(1):69-81.

14- Duran P, Merker A, Briceno G, Colon E, Line D, Abad V, Kenny DelToro K, Chahın S, Matallana AM, Lema A, Llano M, Cespedes J , and Hagenas $L$ (2016) : Colombian reference growth curves for height, weight, body mass index and head circumference. ActaPædiatrica ;105(3):116-125.

15- Esmaeili1 M, Esmaeili M, Saeidi R and Sharbaf FG (2015): Head Circumference in Iranian Infants ,Iranian Journal of Neonatology; 6(1):28-32.

16- AmareEB ,Kiserud $T$ and Juliusson PB (2014) : Early childhood head circumference: Reference ranges for Ethiopian population,World Neurosurgery $\mathbf{. 8 4}$ (6): 1566-1571.
17- Kara B , Etiler N, Uncuoğlu AA , Gen HM , Gmşl EU, Gkay G and Furman A (2016) : Head Circumference Charts for Turkish Children Aged Five to Eighteen Years Arch Neuropsychiatr.53(1): 55-62

18- Chritia-EmandiA ,Doros G , Simina IJ , Gafencu M and Puiu M (2015) : Head circumference References for school aged children in Western

Romania.Rev.Med.Chir.Soc.Med .Nat. Lasi; 119(4):1083-91.

19- Barbier A, Boivin A, Yoon W, Vallerand D, Robert W, Audibert F, Keith J. Barrington, Shah PS, Nuyt AM, and the Canadian Neonatal Network (2013) : New Reference Curves for Head Circumference at Birth, by Gestational Age, Pediatrics;131(4):1158-1167.

20- Yamamah GA, Hassan NE, Elmasry SA, Salama EE and Shouman MG (2010) : South Sinai Growth Charts of Children and Adolescents ; Journal of American Science. 6(10):232-240.

21-Bong Y, Shariff A A, Mohamed A, and Merican AF (2015) : Malaysian growth centiles for children under six years old. Ann Hum Biol, 42(2):108115.

22-Pedersen $M$, von StedingkH ,Botsivali $\mathbf{M}$, Agramunt $\mathrm{S}$, Alexander J , Brunborg $\mathbf{G}$ et.al (2012): Birth weight, head circumference, and prenatal exposure to acrylamide from maternal diet: the European prospective mother-child study (NewGeneris). Environ Health Perspect. 120(12):1739-45. 